\title{
Effects of magnitude of reward increment on positive incentive contrast effects in the rat
}

\author{
LAWRENCE WEINSTEIN \\ University of New Brunswick, Saint John, Canada
}

\begin{abstract}
An increase from $.01 \%$ to $1 \%$ in the concentration of saccharine solution in an operant conditioning box with rats produced positive contrast, while an increment from $.05 \%$ to $1 \%$ failed to result in positive contrast effects. These findings are in agreement with the few studies that have examined the effects of magnitude of reinforcement change on the magnitude of incentive contrast with human and infrahuman organisms. It would appear that amount of reward increment is a variable that controls the occurrence of positive incentive contrast effects in rats.
\end{abstract}

Positive incentive contrast effects are said to occur when an increase in amount of reward results in a significantly higher level of behavior than the performance level of a control group maintained throughout training on the larger quantity of incentive. Negative contrast effects are defined by a reliable reduction in level of performance below a control group level of performance consequent to a decrease in amount of reinforcement.

From Crespi's (1942) earliest demonstration of negative contrast effects subsequent to quantitative variations in reward, the phenomenon has been repeatedly demonstrated up to the present (e.g., Weinstein, 1970a, b; Weinstein \& Colucci, 1970b). Positive contrast, on the other hand, has proved to be as rare as negative contrast is ubiquitous. Subsequent to Crespi (1942) and Zeaman's (1949) studies, the literature was marked with frequent failures to obtain the effect (e.g., Ashida \& Birch, 1964; Collier, Knarr, \& Marx, 1961; Hulse, 1962; Metzger, Cotton, \& Lewis, 1957; Spence, 1956, pp. 130-132; Weinstein \& Colucci, 1970a). Contrary to this earlier trend, a number of recent investigations have demonstrated positive contrast effects with an increment in reward magnitude (e.g., Dunham \& Kilps, 1969; Panskepp \& Trowill, 1969; Shanab \& Ferrell, 1970; Shanab, Sanders, \& Premack, 1969; Weinstein, 1970c). While it is not readily apparent what variables control the occurrence of positive contrast effects, magnitude of reward decrement is one variable that has been demonstrated to affect the magnitude of negative contrast in human and animal subjects. Di Lollo and Beez (1966) and Gonzalez, Gleitman, and Bitterman (1962) have reported that the size of negative contrast effects with animal subjects is a positive function of the amount of reward reduction. Weinstein (1970c) has demonstrated with human organisms the

Requests for reprints should be sent to Dr. L. Weinstein, Assistant Professor of Psychology, Director of Psychological Laboratories, University of New Brunswick, Saint John, New Brunswick, E2L 4L5, Canada. same relationship between amount of negative contrast and size of incentive reduction as has been reported for rats. Few studies, if any, have examined the effects of magnitude of reward increment on positive contrast effects with infrahuman organisms. The present experiment investigated the effect of magnitude of reward increment on positve incentive contrast effects with rats.

\section{METHOD}

Subjects

The subjects, 45 experimentally naive male albino rats between the ages of 90 and 120 days at the start of the experiment, housed three to a cage, were randomly assigned to each of three equal groups.

\section{Apparatus}

The operant conditioning box had plywood side walls, a Plexiglas top, back, and door, a grid floor, and measured $305.8 \times 254 \times 254 \mathrm{~mm}$.

A rectangular hole $12.7 \mathrm{~mm}$ high $\times 50.8 \mathrm{~mm}$ long was cut in the side of the box, $127 \mathrm{~mm}$ above the floor, so that the bar could be inserted $12.7 \mathrm{~mm}$ into the box. A circular hole $9.4 \mathrm{~mm}$ in diam was cut in the floor. Through this opening the subject had access to the .4-cc cup of the dipper when it was presented.

The liquid used was presented to the subject by a dippertype magazine driven by a motor. The metal dipper rested in a plastic tray which contained the liquid reward. The tray was mounted below the hole in the floor, underneath the box; whenever the subject pressed the bar, the cup of the dipper traveled upward $50.8 \mathrm{~mm}$ and was presented for $2 \mathrm{sec}$, during which barpresses were recorded and did not operate the dipper. Two dim houselights illuminated the box. Events were programmed and recorded automatically by timers, counters, etc., located in the experimental room.

\section{Procedure}

Saccharine concentration treatments of $1 \%, .05 \%$, and $.01 \%$ by weight were used with two shift groups $(.05-1$, and $.01-1)$ and control group (1-1). The control group was run throughout the experiment without changing concentrations. The remaining groups were shifted after barpress asymptotes were reached. The .05-1 subjects were changed on Session 20 from $.05 \%$ saccharine to $1 \%$, and the $.01-1 \%$ group was shifted on Session 20 from .01 to $1 \%$ saccharine.

Following several days of adaptation to a food and water deprivation schedule (food and water for $1 \mathrm{~h}$ at the end of the 
experimental time daily), subjects were trained on successive days to press the bar for continuous reinforcement; with each depression, the bar operated the magazine. A session lasted for 40 reinforcements (dipper presentations). This regime was continued until performance appeared to be stable, requiring 19 sessions. Then, on Session 20, concentrations were or were not changed, and all subjects were continued through Session 30. Throughout the study, body weight was recorded daily before each session, and subjects had access to dry pellets and water for $1 \mathrm{~h}$ following the experimental period.

\section{RESULTS}

Body weight data (not presented here) revealed no significant difference between the three groups throughout the pre- and postshift.

The average number of barpresses/minute (barpresses in the session/session duration) was examined in the analysis of the results.

Figure 1 indicates that, during Sessions 1-19, $1 \%$ produced a higher rate of barpressing than did $.05 \%$ or $.01 \%$ saccharine, and $.05 \%$ saccharine resulted in more barpresses/minute than did $.01 \%$. The mean number of barpresses/minute from Sessions 1-19 differed significantly between the three groups by an analysis of variance $[F(2,42)=5.23, p<.05]$. By Neuman-Keuls comparisons, the differences between 1-1 and each of the other groups and between .05-1 and $.01-1$ were each statistically significant $(p<.05)$.

Figure 1 indicates that, on Session 20, .01-1 subjects increased their rate of barpressing to a level above that of the 1-1 animals (positive incentive contrast effects), while the $.05-1$ subjects increased their rate of performance to a level below that of the 1-1 group.

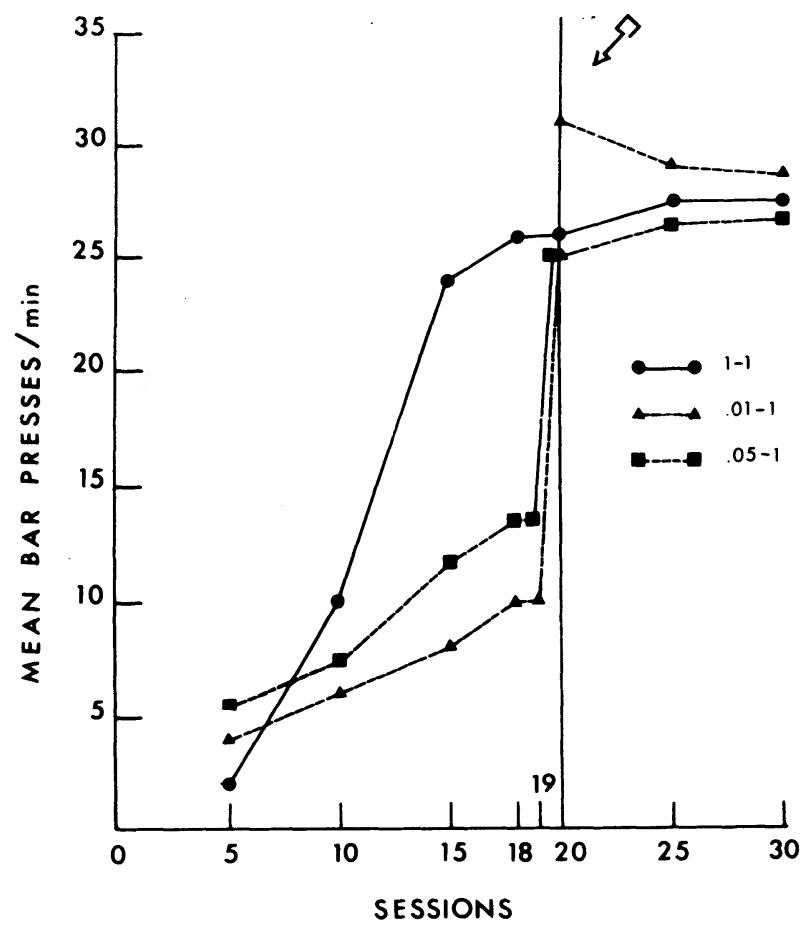

Figure 1. Mean barpresses/minute. Arrow denotes postshift.
The mean number of barpresses/minute during Sessions 20-30 differed reliably among the three groups by an analysis of variance $[\mathrm{F}(2,42)=6.41, \mathrm{p}<.05]$. By Neuman-Keuls comparisons, the difference between $.05-1$ and 1-1 was not significant ( $p>.05$ ), while the difference between $.01-1$ and $1-1$ was statistically reliable $(\mathrm{p}<.05)$.

\section{DISCUSSION}

The finding that for Sessions 1-19 response rate was a monotonic function of reward magnitude indicates that three discriminably different levels of reinforcement were used. During the postshift, positive contrast was obtained for the .01-1 subjects but was not found for the .05-1 group. That is to say, it seems that the likelihood of the phenomenon occurring is a positive function of the magnitude of reward increment. These findings are in accord with the few experiments that have examined the effects of magnitude of incentive increment on the magnitude of positive contrast effects with human subjects (e.g., Weinstein, 1970c). The present results are also in agreement with the previously discussed findings of Di Lollo and Beez (1966) and Gonzalez, Gleitman, and Bitterman (1962), who demonstrated the positive relationship between incentive contrast and amount of variation in quantity of incentive.

The present findings contrast with previous research with saccharine which has failed to obtain positive contrast effects subsequent to an increase in concentration of a saccharine solution (e.g., Hulse, 1962). The most likely reason for the disparity is that Husle used preshift concentrations of $.05 \%$ and $1 \%$, which produce smaller differences in behavior than the present - concentrations, $.01 \%$ and $1 \%$. The present positive contrast effects cannot be attributed to the difference in test situations between Hulse's experiment and the current study, for contrast was not obtained with Hulse's concentrations; therefore, the difference in testing is not a sufficient condition to result in upward contrast effects.

The present data suggest that earlier failures to obtain positive incentive contrast effects may have been a function of the relatively small amounts of reward disparity experienced in the preshift phase.

It would appear that magnitude of reward increment is a variable that determines the occurrence of positive incentive contrast effects.

\section{REFERENCES}

Asmida, S., \& Birch, D. The effects of incentive shift as a function of training. Psychonomic Science, 1964, 1, 201-202.

Collier, G., Knarr, F. A., \& Marx, M. H. Some relations between the intensive properties of the consummatory response and reinforcement. Journal of Experimental Psychology, 1961, 62, 484-495.

Crespi, L. P. Quantitative variations of incentive and performance in the white rat. American Journal of Psychology, 1942, 55, 467-517.

Di Lollo, V. D., \& BEez, V. Negative contrast effect as a function of magnitude of reward decrement. Psychonomic Science, 1966, 5, 99-100.

Dunham, P. J., \& KILPS, B. Shifts in magnitude of reinforcement: Confounded factors or contrast effects. Journal of Experimental Psychology, 1969, 79, 373-374.

Gonzalez, R. C., Gleitman, H., \& Bitterman, M. E. Some observations on the depression effect. Journal of Comparative and Physiological Psychology, 1962, 55, 578-581.

Hulse, S. H. Partial reinforcement, continuous reinforcement, and reinforcement shift effects. Journal of Experimental Psychology, 1962, 64, 451-459.

Metzger, R., Cotton, J. W., \& Lewis, D. J. Effects of reinforcement magnitude and of order of presentation of 
different magnitudes on runway behavior. Journal of Comparative and Physiological Psychology, 1957, 50, 184-188.

Panskepp, J., \& Trowill, J. A. Positive and negative contrast effects with hypothalamic reward. Physiology and Behavior, 1969, 4, 173-175.

Shanab, M. E., \& Ferrell, H. J. Positive contrast obtained in the Lashley maze under different drive conditions. Psychonomic Science, 1970, 20, 31-32.

Shanab, M. E., Sanders, R., \& Premack, D. Positive contrast in the runway obtained with delay of reward. Science, 1969, 164, 724-725.

Spence, K. W. Behavior theory and conditioning. New Haven: Yale University Press, 1956.

Weinstein, L. Negative incentive contrast with saccharine versus sucrose and partial reinforcement. Psychonomic Science, 1970, 21, 276-278. (a)
Weinstein, L. Negative incentive contrast with sucrose. Psychonomic Science, 1970, 19, 13-14. (b)

Weinstein, L. Magnitude of incentive contrast as a function of amount of verbal reward change. Psychonomic Science, 1970, 21, 65-66. (c)

Weinstein, L., \& Colucci, V. M. Increase in incentive amount with verbal reinforcement. Psychonomic Science, 1970, 21, 83-84. (a)

Weinstein, L., \& Colucci, V. M. Negative incentive contrast effects with verbal reinforcement. Psychonomic Science, 1970, 18, 318. (b)

ZeAman, D. Response latency as a function of the amount of reinforcement. Journal of Experimental Psychology, 1949, 39. $466-483$.

(Received for publication October 13, 1976.) 